\title{
Strategies for Sustainable Development of Socio-Economic Systems
}

\author{
NATALIA YU. MOROZ ${ }^{1}$, OLGA V. ANTIPOVA ${ }^{2}$, NADEZHDA YU. PSAREVA ${ }^{3}$, ELENA V. LYAPUNTSOVA ${ }^{4}$ \\ NADEZHDA S. MATVEEVA ${ }^{5}$ \\ ${ }^{1}$ Department of Economic Analysis, KUBAN STATE AGRARIAN UNIVERSITY, RUSSIAN FEDERATION, \\ E-mail: nata-moroz6401@uohk.com.cn \\ ${ }^{2}$ Department of Economics and Enterprise Management, ALMETYEVSK STATE OIL INSTITUTE, RUSSIAN \\ FEDERATION \\ ${ }^{3}$ Department of Economics and Management, ACADEMY OF LABOR AND SOCIAL RELATIONS, RUSSIAN \\ FEDERATION \\ ${ }^{4}$ Department of IBM 7 “Innovative Entrepreneurship”, BAUMAN MOSCOW STATE TECHNICAL UNIVERSITY, \\ RUSSIAN FEDERATION \\ ${ }^{5}$ Department of State and Municipal Management, STATE UNIVERSITY OF MANAGEMENT, RUSSIAN \\ FEDERATION
}

\begin{abstract}
The global trend of sustainable development of the state economies is associated with a systematic approach that provides for comprehensive and interconnected effective business development, environmental protection, and social decisions. The concept of "sustainable development" was first conceived in 1983 by the World Commission for South Africa, was further developed in 1983 by the UN World Commission. In 1987 this concept was reflected by UN World Commission in the report "Our Common Future" to the World Commission. Despite such a long period of existence of the concept of sustainable development, many issues related to the implementation of this concept remain unresolved. One of the most important issues in assessing the sustainable development of socio-economic systems is the choice of criteria. In general, sustainable development of the economy is primarily associated with a person. Thus, the study considers a methodological approach to calculating a consolidated composite index for assessing the sustainability of the development of a national socio-economic system. The purpose of the study was to investigate the main strategies of social and economic development, key challenges and directions of such development, both at the state and private business level. The strategy of an open economy with the active participation of the state is considered on the example of supporting five fundamental sectors of the economy: energy, transport, water supply, sanitation, and forestry. The influence of globalisation on the sustainable development of socio-economic systems through regionalisation is shown - the peculiar political and economic mechanisms of structural transformation aimed at increasing the efficiency of the economies of the countries participating in the integration association.
\end{abstract}

Keywords: sustainable development, socio-economic system, politics, stability index, globalisation, development strategies.

JEL Classification: O35, P20, P31, Z13. 


\section{Introduction}

Sustainable development is a category that can only be attributed to humanity and nature in general. This is an evolutionary process, carried out both by civilisation as a whole and by each specific state, and requires the setting of goals at each stage. The sustainable development of an individual country is part of the sustainable development of all mankind. The strategic goal of sustainable development of Russia is to increase the quality of life of the population based on scientific and technological progress, dynamic development of the economy and social sphere, and the reproductive potential of the country's natural complex to preserve the biosphere and technological potential in the interests of present and future generations (Khamzina et al., 2020; Buribayev et al., 2020). The main prerequisites for the sustainable development of Russia are: a large territory with preserved nonrenewable natural resources and natural ecosystems, human potential and economic resources (De Villiers et al., 2014; Dhaliwal et al., 2014). To achieve sustainable development, it is necessary to preserve areas with natural ecosystems to the maximum possible extent, to rationally use nonrenewable natural resources and human potential. Furthermore, due to the specific demographic situation, it is necessary to provide direct economic resources for the human resources development.

The starting positions and conditions of sustainable development in countries have their own characteristics and determine the need for work to achieve a strategic goal, determining the appropriate stages with their characteristic goals (Galiullina et al., 2018a). The stability of Russia (in the broadest sense) is determined and will for a long time be determined by the availability of its natural resources. Natural resources of Russia are the basis for solving its economic and social problems. Currently, the only way towards sustainable development is the gradual abandonment of the intensive sale of resources, their reasonable economy and fair distribution of natural rent. In addition, Russia's natural resources serve all of humanity: $65 \%$ of the world's wild forests are located there, purifying the air used by all of humanity. Consequently, Russia has the right to raise the issue of global environmental rent before the world. The Kyoto Protocol was the first step towards a fair solution to this problem (Galiullina et al., 2018b).

The goal of the first stage of Russia's sustainable development (short-term perspective) is to overcome the long-term socio-economic, environmental and structural crisis that covered the period of the country's transition to a market economy and a democratic civil society. The tasks of this stage should be implemented in the government's measures to overcome the socio-economic crisis and create conditions for the country's transition to a stable, socially oriented market economy. The market economy should be based mainly on the use of its internal resources: rent for natural resources, intellectual potential and high-tech industries (Domingues et al., 2017; Sigidov et al., 2020; Novoselova et al., 2020; Vasylishyn and Yarova, 2021). At this stage, the foundation of a new Russian economy should be laid, which will ensure effective reproduction and have the potential for long-term dynamic growth and allow solving the problems of increasing the quality of life and modernising production apparatus for maintaining the integrity and security of the country. This requires reinforcement of the economic function of the state, which is associated with the necessary adjustment of the market mechanism and its regulatory bodies (Lu et al., 2019), strengthening the Russian economy, increasing the efficiency of applying the methods of the modern economy. It is assumed that government funding to support high-performance industries, small and medium-sized enterprises, the implementation of environmentally harmful projects or similar consequences is not unambiguous enough (Kiyanova et al., 2018).

The main internal goal of sustainable development should be to consolidate the layered, entrenched bedrock. However, ensuring sustainable development of the socio-economic system and a constant improvement in the quality of life of the population remains difficult for almost every country. Due to the weakness of national socio-economic systems in front of political and economic influence from the outside, all the advantages of openness of international markets and globalisation are nullified (Vasylieva et al., 2020). This requires the use of effective government programmes to ensure sustainable development. Therefore, there is an urgent need to develop a methodology for 
assessing the sustainability. It should be based on the general sustainable development of the main points of influence on the factors improving the living standards of the population as the basis for the economy and political stability in the country (Kookueva \& Tsertseil, 2017; Bliznets et al., 2018).

The concept of "sustainable development" was first conceived in 1983 by the World Commission for South Africa and in 1983 by the World Commission (The Commission was headed by the Prime Minister of Norway G. Bruntland). The concept of sustainable economic development was formulated in the report of this commission "Our Common Future" in 1987 (Antipova et al., 2020). The essence of the concept is to meet human needs in the consumption while preserving the environment. In this context, "sustainable development" includes economic (quantitative growth and qualitative changes in the structure of the economy), social (improving the quality of life of the population) and ecological (environmental protection and social use of natural resources) components (Proskuryakova and Ermolenko, 2019; Lutsenko et al., 2020). According to the concept, implementation is in accordance with the principles of providing opportunities for the development and use of humans as a resource, including the protection of the environment, culture and opportunities, as well as providing similar opportunities for future generations (Nazarova and Gavrusev, 2018; Kutcherov et al., 2020; Kudelinac and Kutcherov, 2020). Notably, all designated were created in the zone of state influence. Therefore, regardless of whether the system of economic management is applied, the main task of the regulator of economic and social processes in the country rests with the legislative and executive authorities.

\section{Materials and Methods}

Considering the essence of the concept of sustainable socio-economic development, it can be stated that the main goal of sustainable development is to improve the quality of life of the population now and in the future. Thus, the main indicator of the effectiveness of the development and implementation of a strategy for sustainable development of national socio-economic systems is the quality of life of the population. Such an indicator can only be measured on the basis of available statistical data, using a consolidated composite index (Kutcherov, 2020; Kudelinac and Kutcherov, 2020; Twerefou et al., 2020).

According to the proposed methodology, the development index of the components of each $j$-th group of indicators is proposed to be calculated as follows:

$$
\text { Index }_{j}=\sum\left(k_{i j} * s_{i j}\right)
$$

where: Index $x_{j}$ - index of the $j$-th group of indicators; $k_{i j}$ - growth rate of the $i$-th indicator in the $j$-th group; $s_{i j}$ - weight of the $i$-th indicator in the $j$-th group Based on this, the consolidated composite index for assessing the sustainability of socio-economic development can be calculated by the equation:

$$
C C I=\sum\left(\operatorname{Index}_{j} * s_{j}\right),
$$

where: $\mathrm{CCl}$ - consolidated composite index for assessing the sustainability of socio-economic development; Index $x_{j}$ - index of the $j$-th group of indicators; $s_{j}$ - weight of the $j$-th group in CCI.

It is proposed to estimate this indicator using basic calculation methods, and to assess the presence of sustainable socio-economic development by the presence of an increase in the index over a period of at least three years (Boeva-Omelechko et al., 2019). The proposed method for calculating the consolidated composite index can also be supplemented, and the weight of each indicator or group can be changed (in this method, the emphasis was on three components: economic, social and environmental). The proposed methodology for calculating the consolidated composite index can be adapted for each individual country or region, depending on the goals set for the next 10-15 years. That is, it can be used for long-term planning, forecasting, and assessment of the effectiveness of the functioning of national socio-economic systems (Pinkovetskaia et al., 2020; Kanashchenkov et al., 2019). The use of this estimate as an indicator of compliance with the socio-economic situation of 
Russia, the situation in the member states of the European Union, can show the prospects for solving such issues as: opening a visa-free regime, expanding the access of 15 national producers to the European market. All equations were used for the further calculation of statistics and the development of methodological proposals for the development of the economy in the country.

Table 1 Methods for calculating the consolidated composite index for assessing the sustainability of the development of the national socio-economic system

\begin{tabular}{|c|c|c|c|}
\hline $\begin{array}{l}\text { Indicator } \\
\text { group }\end{array}$ & Indicator* & $\begin{array}{l}\text { Weight of the } \\
i \text {-th indicator } \\
\text { in the } j \text {-th } \\
\text { group }\end{array}$ & $\begin{array}{l}\text { Group } \\
\text { weight in } \\
\mathrm{CCl}^{*}\end{array}$ \\
\hline \multirow{8}{*}{$\begin{array}{l}\text { Group I. } \\
\text { Economic } \\
\text { component }\end{array}$} & Actual GDP & 0.15 & \multirow[t]{8}{*}{0.4} \\
\hline & Actual GDP per capita & 0.15 & \\
\hline & Physical volume of production & 0.15 & \\
\hline & Capital investment & 0.15 & \\
\hline & Foreign investment in the national economy & 0.10 & \\
\hline & Balance of payments ${ }^{\star \star \star}$ & 0.10 & \\
\hline & Percentage of the processing industry in the total production structure & 0.10 & \\
\hline & Utilisations of energy resources of own production & 0.10 & \\
\hline \multirow{10}{*}{$\begin{array}{l}\text { Group II. } \\
\text { Social } \\
\text { component }\end{array}$} & Natural population growth & 0.15 & \multirow[t]{10}{*}{0.4} \\
\hline & $\begin{array}{l}\text { Population change as a result of movement of citizens across the } \\
\text { state border }\end{array}$ & 0.10 & \\
\hline & Life expectancy of the population & 0.10 & \\
\hline & Economically active population & 0.10 & \\
\hline & Percentage of economically active working population & 0.15 & \\
\hline & Number of jobs created & 0.10 & \\
\hline & The amount of monetary resources allocated to education & 0.05 & \\
\hline & Household real income & 0.10 & \\
\hline & Part (percentage) of household income allocated to investment & 0.10 & \\
\hline & Load per worker & 0.05 & \\
\hline \multirow{4}{*}{$\begin{array}{l}\text { Group III. } \\
\text { Energy } \\
\text { component }\end{array}$} & Consumption of energy sources per capita ${ }^{\star \star \star \star}$ & 0.20 & \multirow[t]{4}{*}{0.2} \\
\hline & $\begin{array}{l}\text { The volume of emissions into the atmosphere per } 1 \mathrm{~km}^{2} \text { of the state } \\
\text { area }\end{array}$ & 0.25 & \\
\hline & The volume of production of alternative (renewable) energy sources & 0.25 & \\
\hline & The number of deaths due to cancer**** & 0.30 & \\
\hline
\end{tabular}

In modern conditions of geopolitical transformations and chronic instability in the world financial and commodity markets, the question of developing a new policy of socio-economic development for national economies has become acute. The main such policy should be based on a long-term perspective based on the concept of future development, taking into account the current trends of regionalisation (regional integration) and globalisation. At the same time, it is necessary to be aware of the essence of these processes.

\section{Results and Discussion}

In modern conditions of geopolitical transformations and chronic instability in the world financial and commodity markets, the question of developing a new policy of socio-economic development for national economies has become acute. The main such policy should be based on a long-term perspective for the development of the economy, the future development of the country's economy, taking into account the current trends of regionalisation (regional integration) and globalisation. At the same time, it is necessary to be aware of the essence of these processes. Globalisation is a process, trend, political and economic movement towards the creation of a world economic system with a single production structure and a single world financial and commodity market. In such a system, capital, goods, services and labour resources move in accordance with certain conditions and rules, taking into account the importance of individual states and integration associations in the world arena. At the same time, there is a unification of regulatory and social protection, economic strategies of coordination by transnational capital (owners of large transnational corporations). Regional 
integration acts to a certain extent as a balancing process of globalisation and is based on the creation and reinforcement of regional intra-economic ties. But at the same time, it is aimed at the most effective integration of the member countries of the association into the financial environment and the economic system (Zhigir, 2019).

Regionalisation takes place through certain political and economic mechanisms of structural transformation of increasing the efficiency of the economies of the countries participating in the integration association. Thus, to maintain the stability of world economic systems, and primarily for the development of national economic systems, the state structures of all countries of the world, without exception, should be engaged in development and implementation of a new policy of socioeconomic development (Bocheliuk et al., 2020). This, in turn, requires the development of new theoretical and methodological approaches. Notably, at this stage there are many theoretical research methods used in modern conditions of the functioning of national economic systems. Thus, further study using the goals of modern state policy of socio-economic development is necessary. This confirms the relevance of the creation of a methodology for the improvement of state socio-economic based on the concepts of socio-economic development, as well as basic strategies.

Economic growth is the process of increasing the existing production volumes of the national product (Orazalin and Mahmood, 2018; Ushakov et al., 2019; Khodiev et al., 2019). At the same time, to maintain a certain level of economic growth, a constant change (adjustment in accordance with market requirements) of the structure of the gross domestic product and the national economy is required. Thus, the process of economic growth and the accompanying structural changes in the economy, in fact, are integral parts of the process of socio-economic development of the state. It should be borne in mind that the dynamics of economic growth has a decisive influence on the dynamics of structural changes in the national economy. An increase or decrease in the rate of economic growth, respectively, leads to the intensification or inhibition of changes in the production structure of the national economy (Bocheliuk et al., 2019). There is also an inverse relationship. Structural changes in the national economy led to an increase in labour productivity and affect the rate and quality of growth of the national economy. As a rule, the new structure of the national economy has a positive effect on economic growth only at a certain stage in the development of the national economy. In subsequent periods, the same economic structure may slow down the development of the national socio-economic system, since it will no longer provide sufficient growth rates of labour productivity and production volumes. Thus, one of the main levers for managing economic growth can be considered the anticipatory elimination of ineffective economic structures that slow down the processes of production development (Bobrova et al., 2020).

Summarising the various ways of state influence on the economic growth in countries with market economies, the main types of development strategies can be identified. The development strategies discussed below are the result of theoretical research, and in practice, various combinations of these strategies have been used or are used. The main problem that needs to be addressed when forming a development strategy is the issue of forming a transformation mechanism for the totality of socioeconomic ties in the national economy. The existing ties in the national economy need to be streamlined in such a way that the national economy will get out of the vicious circle of poverty and enter the spiral of economic growth. Given that the main components of economic growth are labour and capital, the main problem in developing countries is the lack of investment resources for the development of productive potential, as well as human resources. A kind of vicious circle of economic backwardness has been formed (Romaniuk, 2017; Romaniuk, 2020). Countries experiencing a shortage of investment resources find themselves in a narrowed process of production and consumption, which in turn leads to an even greater lack of investment resources for the development of production capacities and human capital. In this regard, the state must formulate development strategies aimed at breaking this vicious circle of poverty and the transition of the national economy to the stage of selfsustaining long-term economic growth. Based on the analysis carried out, five main types of socioeconomic development strategies can be distinguished. 
The first type of strategy is the liberal development strategy. The specificity of this strategy lies in the fact that the improvement of the country's resource allocation system is carried out with the help of market mechanisms and, moreover, with the adaptation of the national economy to those 24 directions indicated by the market. According to this strategy, the sphere of interests of the state's economic policy is the processes occurring at the micro level. This strategy is based on private initiative and entrepreneurship. The strategy is used mainly during the economic crisis, when it is necessary to stabilise prices, supply and demand in the market. A liberal strategy aims to increase the number of disruptions (which are inherently potential investments) and improve the efficiency of capital use. When implementing this strategy, methods of monetary and fiscal policy are used, therefore it is also called a monetary or orthodox strategy. Thus, the liberal strategy is aimed at solving economic policy in the long term in the long term (Poghosyan, 2018).

The second type of economic development strategy is the open economy strategy (Branco et al., 2014). The open economy strategy, like the liberal strategy, focuses on the allocation of resources in the market or in the private sector. At the same time, the leading role in increasing the efficiency of the national economy is assigned to exports (Marshall and Shulsky, 2018). According to this strategy, the global market represents a potential demand for products and thus potentially affects the rate and quality of growth of the national economy. Thus, the national economy should get the most out of international trade, competition in the international market for goods and services is an incentive for entrepreneurs in terms of increasing labour productivity, resource efficiency and quality of products. The effects obtained at the micro level spread to the country's economy as a whole, increase its efficiency and accelerate the pace of development. Thus, an open economy strategy, using comparative advantages and increasing the savings rate, should ultimately lead to faster investment and more efficient use of investment resources. In contrast to the liberal strategy, the state plays an active role in the open economy strategy. The state proposes a policy to stimulate supply, remove barriers to the export of products, implement an accessibility policy, and use policies to stimulate product exports. At the same time, the state should pursue a policy of liberal trade and stimulate the inflow of foreign investment (Shtal et al., 2020; Kuzmenko et al., 2020).

The third type of strategy is the industrialisation strategy. Like previous strategies, this strategy is aimed at stimulating the growth of the national economy. The specificity of this strategy lies at the heart of our national economy. In the implementation of this strategy, the leading role is assigned to the state, which at various levels should restrain accumulating investment resources and direct them to increase industrial production.

The study considers innovative financing mechanisms for the five most important sectors of the economy: energy, transport, water supply, sanitation, and sustainable forestry. They have several common features; all five sectors are strategic, as defined in Agenda 21. This means that, in addition to their key role in economic development, they are also strategically important for poverty reduction, equity, environmental protection and environmental sustainability. Secondly, all five sectors have serious financial problems, which require mobilisation, both domestic and international. Third, all five sectors have in the past been the main recipients of official development assistance (ODA) from both bilateral and multilateral sources; they have been hit by declining ODA in recent years, with the possible exception of the forestry sector. Fourth, all five sectors require large initial capital investment, have long paybacks over a long period of time (electricity, transport, and water supply) or long-term returns (forestry), which present cash flow cost recovery problems. The activity of these sectors depends mainly on external factors, which makes it difficult to attract finance, reduces the interest of investors/decision-makers due to the complexity of cost recovery. Finally, all five sectors have traditionally been "monopolised" by the public sector due to the nature of their natural monopoly and their aspects of public good. In all five sectors, there is a growing awareness of the need and opportunities for private sector participation in both financing and governance.

Despite the similarities, there are also significant differences between these sectors. First, electricity, water, and transport are essentially private goods, the production and consumption of which results in certain waste by-products or side effects (such as air and water pollution and 
congestions). The predominantly private nature of electricity, water, and transportation services means that the individual's willingness to pay is potentially high enough to recover costs. Perhaps the exclusion of those who do not pay, and freeriding is less of a problem; therefore, there are good prospects for the provision of the private sector and private financing. In contrast, sanitation (including wastewater collection and treatment) and sustainable forestry are predominantly public goods with some aspects of private good (e.g., local sanitation and non-wood forest products). The implication is that willingness to pay is low, exclusion of defaulters is difficult (and not recommended), and free riders are the rule rather than the exception. This means that cost recovery is potentially difficult, incentives for private sector provision of services are limited, and in the absence of a steady stream of revenues, fundraising requires government subsidies and / or government guarantees. A second important difference is that while energy, transport and forestry have significant global implications for public use, water and sanitation only have local implications. $\mathrm{CO}_{2}$ emissions from the burning of fossil fuels, whether for generation of electricity or transportation, and deforestation increase the concentration of greenhouse gases that increase the risk of global warming. This means that changes in the structure of energy consumption and transport, as well as in land use in one country are of concern to other countries and the international community (Marshall and Shulsky, 2018).

On the other hand, investments in renewable energy sources, more efficient public transport systems, forest conservation and reforestation provide significant global benefits that can be enjoyed free of charge. This means that investments in energy, transport, and forestry have global value and, if they can be captured somehow, they can be used to finance those investments. Indeed, the Global Environment Facility and the Clean Development Mechanism can help capture and reinvest some of these global values. Investments in water and sanitation are not of the same global interest, but should also be of concern as they represent an important component of the social dimensions of sustainability (Mahmood and Orazalin, 2017; Mahoney et al., 2013; Diegtiar et al., 2020).

The third obvious difference between sustainable forestry, especially reforestation, and all other sectors is that the investment costs and returns are divided over many years, if not decades. This requires long-term bridging financing to address the very complex cost flow problem, especially in developing countries, where usually only short-term loans are available (Grossman, 1981; Gul and Leung, 2004). Tools for collecting environmental values such as ecotourism, bioprospecting, watershed conservation fees and carbon offsetting help generate a steady stream of income to secure long-term loans as well as reduce cash shortages. The fourth difference is that foreign capital in economic assets such as power plants, water supply systems, sewage treatment plants, and transportation systems is more acceptable to developing countries than foreign capital in natural resources such as forests and national parks. On the other hand, forests and water supply systems are more easily publicly owned and managed than public transport systems and power plants.

Today, the priority for the Russian Federation, as for most countries of the world, is overcoming the consequences of the economic crisis, creating a competitive, innovative economy that contributes to the well-being of citizens and ensuring equal opportunities for them. The key challenges to sustainable development today and in the long term for the Russian Federation:

1. increased global competition for the factors that determine the competitiveness of innovation systems;

2. demographic problems - aging/decline of the population, migration processes that increase the social burden. Today, 143 million people live in Russia. Although since 2000 the natural population decline has decreased by 7.3 times, and life expectancy in Russia has exceeded the 70-year mark, no natural population growth has yet been observed;

3. climate change;

4. pollution. Today 56.3 million people ( $55 \%$ of the urban population) live in highly polluted urban areas;

5. ecosystem degradation;

6. problems of ensuring food security on a global scale; 
7. growing demand for energy in Russia and in the world;

8. an increase in the amount of waste, including hazardous waste, and the problem of eliminating the accumulated environmental damage.

Key pathways or responses to the challenges of sustainable development include the following:

1. A new concept of environmental and economic development is necessary, including the creation of new production and consumption patterns based on the energy efficiency of the economy and productivity, without additional pressure on natural resources and the climate system. At the same time, the development of an innovative, energy efficient "green" economy and the introduction of "green" technologies that help minimise environmental damage are beneficial from an environmental and economic standpoint. Economic growth can be justified only when the interests of the economy and the task of preserving nature are in a state of reasonable balance, sustainable in the long term. This growth is expected to minimise the associated environmental and social costs.

2. Economic growth is associated with an increase in energy demand. The basic concept of sustainable energy should include issues of access to modern forms of energy, increasing the efficiency of energy consumption, switching to cleaner energy sources, energy sources diversification (including the development of energy production from renewable sources), taking into account the natural potential for their development.

3. Reasonable and civilised attitude to nature should be a prerequisite for development programmes and implementation of large infrastructure projects. Environmental quality is a key factor in the competitiveness of an economy, but at the same time it should not create barriers or encourage hidden discrimination in international trade.

4. The concept of sustainable development is perceived by the business community as one of the elements of competition. The state should establish obligations for public companies on sustainable development policy, including regular non-financial reporting.

5. Sustainable development should facilitate the participation of all members of society in economic and political life, but especially people with disabilities. Currently, there are about 13 million people with disabilities in Russia ( $8.8 \%$ of the population).

6. For more than a thousand years, representatives of more than 180 people of different nationalities and religions have been living on the territory of the Russian Federation. Multinationality is a unique advantage of Russia. Sustainable development should support the harmonisation of interethnic relations, as well as the preservation of the natural habitat, traditional way of life and cultural values of the 40 indigenous peoples living in the Russian Federation.

7. Peace, development, and nature are interdependent and inseparable. Conflict inhibits and repels development. There can be no lasting and sustainable peace when natural resources that provide an adequate standard of living and adequate functioning of ecosystems are damaged or destroyed. A new paradigm of global development - ensuring peace and global security.

8. Sustainable development presupposes the creation of a security system taking into account natural threats and anthropogenic disasters, including dangerous weather and climatic phenomena. For this, it is necessary to improve the national monitoring and warning system, carry out their technical re-equipment and strengthen the scientific base of forecasting activities. International cooperation is of great importance in this area.

9. One of the important places in the new paradigm of sustainable development should be assigned to science. It should stimulate technological progress in all spheres of life and create scientific substantiation for political and economic decisions.

10. Education plays a key role in achieving sustainable development. It is necessary to improve the quality of education, organise environmental education at all stages of school education, and foster a respect for nature. More educated people make more rational choices. Attitudes and 
behaviour patterns formed in people in childhood play a significant role for the future innovative development. Equally important are the moral aspects of education, which should evoke in everyone a sense of interdependence and universal responsibility for the prosperity of people and the entire living community. Priority should be given to the development of the spiritual and moral foundations of all social communities, including the support of interfaith dialogue at the global and regional levels.

11.Specific sustainable development goals (and therefore indicators) should be set by countries to reflect their national identity and needs, thus ensuring the relevance of the measures taken and national development priorities.

12. Monitoring the achievement of the sustainable development goals will require new indicators that reflect economic growth, the environmental and social dimensions of development, and the social and environmental costs of economic growth. At the same time, such new indicators should not create barriers or be a means of hidden discrimination in international trade.

13.Sustainable development also implies effective interaction of all levels of government, professionalism and competence of decision-makers on interrelated issues of socio-economic development and environmental protection, as well as the participation of civil society in political decision-making.

\section{Conclusion}

It has been substantiated that the achievement of sustainable development of national socioeconomic systems is possible only if the state actively intervenes in the mechanisms of the market economy. This conclusion was made according to the proposed methodology for sustainable development of national socio-economic systems, which served as the basis for the development of the concept of state policy for managing the sustainable development of the socio-economic system of Russia. The study proposes to understand the methodology of sustainable development of national socio-economic systems as a set of scientific theories, ideas and principles, methods and models. All above factors are aimed at maintaining the necessary rates and quality of economic growth based on the structural adjustment of the national economy through active state intervention in the mechanisms of the market economy.

The methodology for assessing the sustainable development of national socio-economic systems has been substantiated. It covers the main aspects of the functioning of the state, and each individual aspect contains the factors of sustainable development of the national socio-economic system. Due to the fact that the factors included in this assessment are expressed in different equivalents and cannot be compared, the methodology is based on the developed consolidated composite index.

\section{References}

1. Antipova, O.V., Sigidov, Y.I., Akhmetshin, E.M., Tabeykina, E.K., \& Akulich, O.V. (2020). Theoretical and methodological pillars of sustainable economic development. Asia Life Sciences, 22(2), 697710.

2. Bliznets, I.A., Kartskhiya, A.A., \& Smirnov, M.G. (2018). Technology transfer in digital era: legal environment. Tarih Kültür ve Sanat Araştırmaları Dergisi - Journal of History Culture and Art Research, 7(1), 354-63.

3. Bobrova, A.V., Stepanov, E.A., Sakulyeva, T., Zhumabekova, G.Z., \& Yesturliyeva, A.I. (2020). The influence of alternative fuels on the development of large-scale production. Journal of Environmental Accounting and Management, 8(4), 335-49.

4. Bocheliuk, V.I., Panov, N.S., Fedorenko, M.I., Zhuzha, L.A., \& Cherepiekhina, O.A. (2019). Gender particularities of value ideals of chiefs. Prabandhan: Indian Journal of Management, 12(10), 33-43. 
5. Bocheliuk, V.Y., Denysov, S.F., Denysova, T.A., Palchenkova, V.M., \& Panov, N.S. (2020). Psychological and legal problems for ensuring human rights. Rivista di Studi sulla Sostenibilita, 2020(1), 235-45.

6. Boeva-Omelechko, N.B., Posternyak, K.P., Zheltukhina, M.R., Ponomarenko, E.B., Talybina, E.V., Kalliopin, A.K., \& Ovsyannikova, M.N. (2019). Two images of Russia in the British political mass media discourse of 1991-1993 and 2013-2019: pragmastylistic aspect. Online Journal of Communication and Media Technologies, 9(4), e201926.

7. Branco, M.C., Delgado, C., Ferreira Gomes, S., \& Cristina Pereira Eugénio, T. (2014). Factors influencing the assurance of sustainability reports in the context of the economic crisis in Portugal. Managerial Auditing Journal, 29(3), 237-52.

8. Buribayev, Ye., Khamzina, Zh., Belkhozhayeva, D., Meirbekova, G., Kadirkulova, G., \& Bogatyreva, L. (2020). Human dignity - the basis of human rights to social protection. Wisdom, 16(3), 143-55.

9. De Villiers, C., Low, M., \& Samkin, G., (2014). The institutionalisation of mining company sustainability disclosures. Journal of Cleaner Production, 84, 51-8.

10.Dhaliwal, D.S., Li, O.Z., Tsang, A., \& Yang, Y.G., (2014). Corporate social responsibility disclosure and the cost of equity capital: the roles of stakeholder orientation and financial transparency. Journal of Accounting and Public Policy, 33(4), 328-55.

11.Diegtiar, O.A., Hornyk, V.H., Kravchenko, S.O., Karlova, V.V., \& Shtal, T.V. (2020). Improving public water resources policy in Ukraine: Municipal and environmental issues. Journal of Environmental Management and Tourism, 11(3), 669-75.

12.Domingues, A.R., Lozano, R., Ceulemans, K., \& Ramos, T.B., (2017). Sustainability reporting in public sector organisations: exploring the relation between the reporting process and organisational change management for sustainability. Journal of Environmental Management, 192, 292-301.

13.Galiullina, G.F., Aetdinova, R.R., Makarov, A.N., \& Vasilyev, A.E. (2018a). Classification of territories of advanced socio-economic development. Dilemas Contemporaneos-Educacion Politica y Valores, 6, 1-22.

14.Galiullina, G.F., Mironova, T.N., Makarov, A.N., \& Sharamko, M.M. (2018b). The concept and the means of agglomeration processes controlling. Amazonia Investiga, 7(17), 328-34.

15.Grossman, S.J. (1981). The informational rule of warrants and private disclosure about product quality. Law and Economics, 24(3), 461-84.

16.Gul, F.A., \& Leung, S., (2004). Board leadership, outside directors' expertise and voluntary corporate disclosures. Journal of Accounting and Public Policy, 23(5), 351-79.

17.Kanashchenkov, A.I., Novikov, S.V., \& Iniesta, D.S.V. (2019). Technology formation of the mission of micro-level management enterprise in aviation. International Workshop Advanced Technologies in Material Science, Mechanical and Automation Engineering - Mip: Engineering - 2019, 537, 042040.

18.Khamzina, Zh., Buribayev, Ye., Yermukanov, Ye., \& Alshurazova, A. (2020). Is it possible to achieve gender equality in Kazakhstan: Focus on employment and social protection. International Journal of Discrimination and the Law, 20(1), 5-20.

19.Khodiev, B.Yu., Mustafakulov, S.I., Tursunov, B.O., Sigidov, Y.I., \& Khavrova, K.S. (2019). Methods for control efficiency evaluation of the production capacities application at the textile enterprises and the mechanism for optimal control. Astra Salvensis, 499-521.

20.Kiyanova, L.D., Litvinenko, I.L., Laptev, S.V., \& Filina, F.V. (2018). Socioeconomic and management aspects of the system of vocational guidance for learners with disabilities. Tarih Kultur Ve Sanat Arastirmalari Dergisi - Journal of History Culture and Art Research, 7(1), 341-53.

21.Kookueva, V.V., \& Tsertseil, J.S. (2017). Problems of minimum salary in Russia. 4TH BECI International Conference on Business and Economics 2017, 1, 66-79.

22.Kudelinac, A., \& Kutcherov, V. (2020). Wind energy in Russia: the current state and development trends. Energy Strategy Reviews, 34, article number 100627. 
23.Kutcherov, V., Morgunova, \& M., Bessel, A. (2020). Lopatin Russian natural gas exports: an analysis of challenges and opportunities. Energy Strategy Reviews, 30, article number 100511.

24.Kuzmenko, S.H., Filipenko, T.V., Ryabev, A.A., Tonkoshkur, M.V., \& Shtal, T.V. (2020). Current conditions, causes and increase of poverty in Ukraine. Asia Life Sciences, 22(2), 43-56.

25.Lu, X., McElroy, M.B., \& Kiviluoma, J. (2009). Electricity from wind: global perspective with detailed application to the US. Proceedings of the National Academy of Sciences of the United States of America, 106(27), 10933-8

26.Lutsenko, A., Vykluk, M., Skoryk, M., \& Hromova, T. (2020). Fiscal regulation concept formation of the ukraine's economy development. Estudios De Economia Aplicada, 38(4), 3997.

27.Mahmood, M., \& Orazalin, N. (2017). Green governance and sustainability reporting in Kazakhstan's oil, gas, and mining sector: evidence from a former USSR emerging economy. Journal of Cleaner Production, 164, 389-97.

28. Mahoney, L.S., Thorne, L., Cecil, L., \& LaGore, W., (2013). A research note on standalone corporate social responsibility reports: signaling or greenwashing? Critical Perspectives on Accounting, 24(45), 350-9.

29.Marshall, A.W., \& Shulsky, A.N. (2018). Assessing sustainability of command economies and totalitarian regimes: the Soviet case. Orbis, 62(2), 220-43.

30.Nazarova, J., \& Gavrusev, S. (2018). Prospects for renewable energy industry in Russia to solve unemployment problems. National Interests: Priorities and Security, 14, 1649-64.

31.Novoselova, I., Potravnya, I., \& Novoselova, V. (2020). Compensation fund as a tool for sustainable development of the Arctic indigenous communities. Polar Science, 7, article number 100609.

32.Orazalin, N., \& Mahmood, M. (2018). Economic, environmental, and social performance indicators of sustainability reporting: evidence from the Russian oil and gas industry. Energy Policy, 121, 709.

33.Pinkovetskaia, I.S., Arbelaez-Campillo, D.F., Rojas-Bahamon, M.J., Novikov, S.V., \& Iniesta, D.S.V. (2020). Social values of entrepreneurship in modern countries. Amazonia Investiga, 9(28), 6-13.

34.Poghosyan, V. (2018). Philosophies of social behavior research: Meta-analytic review. Wisdom, 11(2), 85-92.

35.Proskuryakova, L.N., \& Ermolenko, G.V. (2019). The future of Russia's renewable energy sector: trends, scenarios and policies. Renewable Energy, 143, 1670-86.

36.Romaniuk, A. (2017). Basic universal units and components of romantic discourse based on dating show patterns of dyadic interaction. Analele Universitatii din Craiova - Seria Stiinte Filologice, Lingvistica, 39(1-2), 370-80.

37.Romaniuk, O. (2020). The first impression matters: The art of male romantic communication in American media dating culture. Discourse and Interaction, 13(1), 67-91.

38.Shtal, T.V., Uvarova, A.I., Proskurnina, N.V., \& Savytska, N.L. (2020). Strategic guidelines for the improvement of logistic activities of trade enterprises. Journal of Information Technology Management, 12(3), 69-81.

39.Sigidov, Yu.l., Korovina, M.A., \& Vlasova, N.S. (2020). Analysis of financial reporting as a method of detection of the facts of falsification. In: Advances in Economics, Business and Management Research: International Conference on Economics, Management and Technologies, 139, 77-80.

40.Twerefou, D. K., Turkson, F. E., Wiafe, B. F., \& Darkwah, S. A. (2020). Do foreign financial inflows impact on economic growth? evidence from sub-saharan africa. Estudios De Economia Aplicada, 38(2),3293.

41.Ushakov, D.S., Sigidov, Y.I., Gribincea, A., Birca, I., \& Mashal, L. (2019). Governance efficiency in conditions of the world economy globalization and digitalization. Journal of Advanced Research in Law and Economics, 10(8), 2566-73. 
42.Vasylieva, O.I., Slukhai, S.V., Khadzhyradieva, S.K., Klochko, A.A., \& Pashkova, A.G. (2020). Ukrainian civil service: implementation of the public administration reform strategy in Ukraine. Journal of Advanced Research in Law and Economics, 11(4), 1439-45.

43.Vasylishyn, S., \& Yarova, V. (2021). Analytical provision of socio-economic security management at macro and microlevels. Estudios De Economia Aplicada, 38(4), 3965.

44.Zhigir, A.A. (2019). Methodology for evaluating effectiveness and forecast of the digital economy projects. Advances in Economics, Business and Management Research, 105, 290-2. 